\title{
Soluble collagen dissolution and assembling in pressurized carbon dioxide water solutions
}

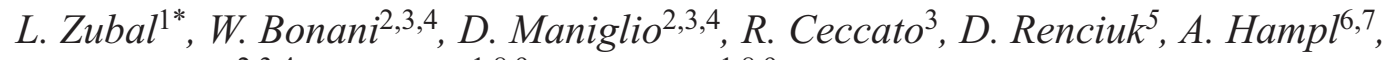 \\ C. Migliaresi ${ }^{2,3,4}$, J. Jancar ${ }^{1,8,9}$, L. Vojtova ${ }^{1,8,9}$
}

${ }^{1}$ Central European Institute of Technology, Brno University of Technology, Purkynova 656/123, 61200 Brno, Czech Republic

${ }^{2}$ BIOtech Research Center and European Institute of Excellence on Tissue Engineering and Regenerative Medicine, Via delle Regole 101, 38123 Trento, Italy

${ }^{3}$ Department of Industrial Engineering, University of Trento, Via Sommarive 9, 38123 Trento, Italy

${ }^{4}$ INSTM - National Interuniversity Consortium of Materials Science and Technology, Trento Research Unit, Via

Sommarive 9, 38123 Trento, Italy

${ }^{5}$ Institute of Biophysics, Academy of Sciences of the Czech Republic, v.v.i., Kralovopolska, CZ-612 65 Brno,

Czech Republic

${ }^{6}$ Department of Histology and Embryology, Faculty of Medicine, Masaryk University, Brno, Czech Republic

${ }^{7}$ International Clinical Research Center, St. Anne's University Hospital Brno, Brno, Czech Republic

${ }^{8}$ Faculty of Chemistry, Brno University of Technology, Purkynova 118, 61200 Brno, Czech Republic

${ }^{9}$ SCITEG, a.s., U vodarny 2965/2, 61600 Brno, Czech Republic

Received 7 July 2017; accepted in revised form 2 October 2017

\begin{abstract}
Dissolution and gelation procedures have a great influence on gelation time, microstructure and mechanical properties of reconstituted collagen products. We have investigated the dissolution of atelocollagen in $\mathrm{CO}_{2} /$ water solutions at low temperature $\left(4^{\circ} \mathrm{C}\right)$ at different $\mathrm{CO}_{2}$ pressures $(0.3-0.9 \mathrm{MPa})$, as well as gelation kinetics and physico-chemical properties of the hydrogel obtained after $\mathrm{CO}_{2}$ removal. Compared to conventional methods, the $\mathrm{CO}_{2}$-assisted technique resulted in faster soluble collagen dissolution and faster gelation into transparent gels characterized by thin $10 \mathrm{~nm}$ fibrils. Electrophoresis and CD spectroscopy demonstrated that the process did not denature the soluble collagen. The possibility to obtain collagen dissolution and gelation without the use of chemical agent other than water and $\mathrm{CO}_{2}$ makes this process particularly appealing for biomedical applications.
\end{abstract}

Keywords: biocompatible polymers, collagen fibrillogenesis, structural analysis, viscoelastic properties, protein self-assembly

\section{Introduction}

Collagen is the most abundant protein in humans and other mammals. It forms the extracellular matrix of cells, having structural, biochemical and signalling functions [1]. Insoluble collagen is widely used as allogenic transplant, as decellularized tissue [2], or as collagen fibers $[1,3]$.

Due to the intensive intermolecular crosslinking of the triple-helix structure, the dissolution of collagen into the single $\alpha$-chains constituents requires the use of acids and enzymes such as pepsin and protease $[4,5]$. Collagen obtained through enzymatic (pepsin) solubilisation goes under the name of atelocollagen, and it is largely used in the gel form in medicine and cosmetics [6]. Atelocollagens extracted from different species present limited differences and are based on the Glycine-X-Y amino acid sequence, where $\mathrm{X}$ and $\mathrm{Y}$ are often proline and hydroxyproline, respectively. 
While maintaining for the most part the properties and the activity of the native insolubilized collagen, atelocollagen presents lower antigenicity due to removal of the collagen telopeptides during the process of enzymatic solubilisation [7].

Impurities like gelatin, aggregates of insoluble collagen, non-fibrillar collagen types and elastin are known to influence the kinetics of gelation, immunogenic potential and mechanical properties of the final product [8]. However, atelocollagen generally presents a higher purity when compared to the acid-solubilized counterpart. Purified atelocollagen is soluble under aqueous acidic conditions at $\mathrm{pH} 3-4$, while it is not usually soluble in water at neutral and physiological $\mathrm{pH}$.

The preparation of collagen-based hydrogels and constructs usually consists of two steps, namely atelocollagen dissolution and thermally-induced sol-gel transition [9-11]. First, atelocollagen is dissolved in diluted acid solution at low temperature $\left(4-10^{\circ} \mathrm{C}\right)$ using hydrochloric acid or acetic acid water solutions as solvents [7, 12-14]. The sol-gel transitions is later obtained by adjusting the $\mathrm{pH}$ of the solution in the range 6.5 to 8 using sodium hydroxide $(\mathrm{NaOH})$ in phosphate buffered solution (PBS) or (4-(2-hydroxyethyl)-1-piperazineethanesulfonic acid) (HEPES) at room temperature or $37^{\circ} \mathrm{C}[10,11]$.

The resulting hydrogel still incorporates all the chemical agents used for collagen dissolution and gelation, with possible negative implications for cosmetic and biomedical applications.

Carbon dioxide $\left(\mathrm{CO}_{2}\right)$ readily dissolves in water with a solubility of $90 \mathrm{~cm}^{3}$ of $\mathrm{CO}_{2}$ per $100 \mathrm{~mL}$ of water at room temperature. The dissolved $\mathrm{CO}_{2}$ is in

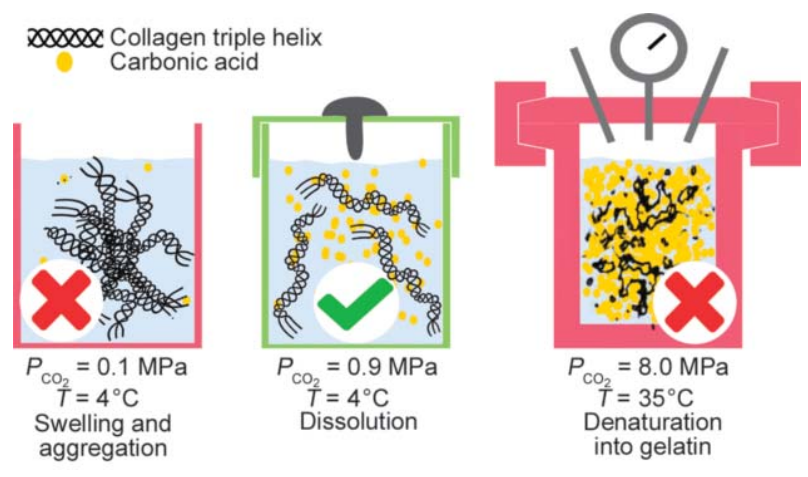

Figure 1. Solubility and stability of soluble collagen at different $\mathrm{CO}_{2}$ pressure and temperature

chemical equilibrium with carbonic acid $\left(\mathrm{H}_{2} \mathrm{CO}_{3}\right)$. In turn, $\mathrm{H}_{2} \mathrm{CO}_{3}$ is a weak acid and in water can dissociate into the deprotonated forms hydrogen carbonate $\left(\mathrm{HCO}^{3-}\right)$ and carbonate $\left(\mathrm{CO}_{3}{ }^{2-}\right)$ with the liberation of protons $\left(\mathrm{H}^{+}\right)$. Overall, the net effect of $\mathrm{CO}_{2}$ dissolution in water is a decrease of $\mathrm{pH}$. As a consequence of Henry's Law, the amount of $\mathrm{CO}_{2}$ dissolved in water increases (and $\mathrm{pH}$ deceases) when reducing the temperature and increasing the $\mathrm{CO}_{2}$ pressure (Figure 2a right) [15].

Previous attempts to extract soluble collagen (Figure $2 \mathrm{~b}$, stars $)$ at higher temperatures $\left(20-37^{\circ} \mathrm{C}\right)$ and $\mathrm{CO}_{2}$ pressures 1-5 MPa yielded pure gelatin, according to the presented Circular Dichroism (CD) spectroscopy (missing peak at $221 \mathrm{~nm}$ ) and sodium dodecyl sulfate polyacrylamide gel electrophoresis (SDS-PAGE) missing the typical collagen fingerprint of an intensive band below $37 \mathrm{kDa}$ and broad range of molar mass [16]. From these results, it was concluded that the entire region $\mathrm{C}$ (Figure 2b, Figure 1 right) is unsafe for soluble collagen processing. However region $\mathrm{C}$ should be still useful for insoluble

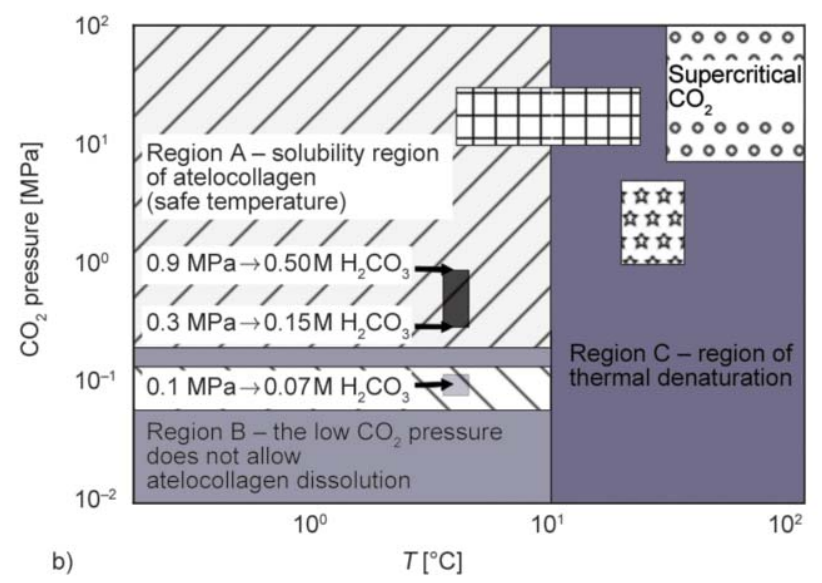

Figure 2 a) Solubility of carbonic acid in water as function of pressure and temperature, the curves were calculated according to Duan et al. [15] measurements/model. b) $\mathrm{CO}_{2}$ pressures and temperatures used for soluble collagen processing in present work (region A) and overview of similar previous works. 
collagen processing in pressurized $[17,18]$ or supercritical conditions [19-21]. Other previous studies on atelocollagen processing in carbonic acid at atmospheric pressure (Region B, Figure 2b, Figure 1 left) [22], lacked sufficient carbonic acid concentration $(<0.07 \mathrm{M}$, Figure 2a left [15]) causing soluble collagen just to swell.

From these results we can assert that the combination of both high pressure (0.3-0.9 MPa) and low temperature $\left(4^{\circ} \mathrm{C}\right.$ ) (Figure $2 \mathrm{~b}$ region $\mathrm{A}$, Figure 1 center) should represent optimal conditions to allow solubilisation [15]. The low temperature also ensures stability of soluble collagen at storage temperatures below $10^{\circ} \mathrm{C}$ [23-26]. The grey rectangle on Region A (Figure $2 b, 0.3-0.9 \mathrm{MPa}$ ) points to experimental conditions used in presented work.

In this work, we have investigated the formation of atelocollagen gels by dissolving bovine type I atelocollagen in pressurized carbon dioxide water solutions and its gelation as a consequence of depressurization. We proved that atelocollagen solution remained stable in a pressurized $\mathrm{CO}_{2}$ atmosphere and that the increase of the solution $\mathrm{pH}$ increase due to $\mathrm{CO}_{2}$ extraction causes the formation of collagen gel containing thin banded fibrils with diameter of about $10 \mathrm{~nm}$.

\section{Materials and methods}

\subsection{Materials}

Type I Bovine Atelocollagen solution PureCol ${ }^{\circledR}$ $\left(0.01 \mathrm{M}\right.$ hydrochloric acid solution $3 \mathrm{mg} \cdot \mathrm{mL}^{-1}$, $\mathrm{pH}$ 2.0) was purchased from Advanced BioMatrix, (San Diego, CA, USA) and used either as it is or as a powder after freeze-drying (Lyophilizer Martin Christ Alpha $2-10$ for 2 days at $-80^{\circ} \mathrm{C}$ ). The isoelectric point of $\mathrm{PureCo}^{\circledR}$ is reported following the producer datasheet to range from $\mathrm{pH} 7$ to 8 .

Prior to drying, the PureCol ${ }^{\circledR}$ solution was dialyzed against deionized water (DI) water (Helix, Millipore, Temecula, CA, USA) for three days using Spectra/ Por $^{\mathbb{B}}$ dialysis tubing (MWCO $15 \mathrm{kDa}$, Spectrum Labs, CA, USA). Liquefied carbon dioxide, with gas purity greater than 99.5 vol\%, was acquired from Air Liquide (Milan, Italy). $\mathrm{NaOH}$, acetic acid (AA) and PBS were purchased from Lachner (Neratovice, Czech Republic) and Sigma Aldrich (St. Louis, Missouri, USA), respectively. For the preparation of collagen solutions in $\mathrm{CO}_{2} /$ water, $10 \mathrm{~mL}$ polypropylene (PP) bottles with a perforated PP cup, connected to the $\mathrm{CO}_{2}$ reservoir via Fizz giz valves (Jamestown, $\mathrm{NC}$, USA) were used (Figure 5a).

\subsection{Control atelocollagen self-assembly}

As control, atelocollagen gels were prepared with the standard procedure, as follows. $0.1 \mathrm{~mL}$ of PBS $10 \mathrm{x}$ was added to $0.8 \mathrm{~mL}$ of $\mathrm{PureCol}^{\circledR}$ solution $\left(3 \mathrm{mg} \cdot \mathrm{mL}^{-1}\right)$ at $4{ }^{\circ} \mathrm{C}$, the $\mathrm{pH}$ was adjusted to $7.3-7.5$ by adding $0.1 \mathrm{M} \mathrm{NaOH}$, finally DI water was added to a final volume of $1 \mathrm{~mL}$ and the solution was kept overnight at $37^{\circ} \mathrm{C}$ in an incubator. To study the effect of $\mathrm{pH}$ in the range 3 to $8,0.1 \mathrm{M} \mathrm{NaOH}$ was added to $0.1 \mathrm{M}$ acetic acid (AA) atelocollagen solutions [27]. Then the solutions were stored overnight at $4{ }^{\circ} \mathrm{C}$ and centrifuged for $30 \mathrm{~min}$ at $10000 \mathrm{~g}$ in order to remove precipitated (self-assembled) atelocollagen. The amount of solubilized atelocollagen left in the supernatant was detected by CD spectroscopy at $221.5 \mathrm{~nm}$ (Jasco J-710, quartz, $2 \mathrm{~mm}$ path length). Detected CD spectroscopy value at $\mathrm{pH} 3$ was taken as soluble $100 \%$ reference. Gelled collagen of other samples were calculated as the percentage variation with respect to the reference (Equation (1)):

$$
\left(\frac{\mathrm{CD}_{\text {reference }}-\mathrm{CD}_{\text {sample }}}{\mathrm{CD}_{\text {reference }}} \cdot 100\right)
$$

\subsection{Dissolution kinetics of atelocollagen powder at different conditions}

Dissolution of freeze-dried atelocollagen powders in different solvents (AA- 0.1 and $0.5 \mathrm{M}, \mathrm{H}_{2} \mathrm{O}$ and carbon dioxide $\mathrm{CO}_{2}$ water solutions in equilibrium with $\mathrm{CO}_{2}$ atmospheres at 0.5 and $0.9 \mathrm{MPa}$ pressure) was determined by measuring the concentration of solubilized atelocollagen at fixed time intervals during the dissolution process (every time the sample was pressurized and depressurized for sampling and measurement). The concentration of solubilized atelocollagen was determined with MicroBCA ${ }^{\circledR}$ Protein Assay Kit (Thermo Scientific) following the manufacturer's instructions. Absorbance values from a microplate reader (Infinite 200, TECAN) at $562 \mathrm{~nm}$ were correlated to the dissolved atelocollagen concentration. Concentration of $0.5 \mathrm{M}$ AA at final time point was taken as reference $(100 \%)$ as the $0.5 \mathrm{M} \mathrm{AA}$ is the most common solvent used in literature.

\subsection{Atelocollagen denaturation detection by circular dichroism}

CD spectroscopy was used in order to quantify atelocollagen denaturation during the experimental procedures using a dedicated analysis protocol modified from [27]. The above defined $\mathrm{CO}_{2}$ and $\mathrm{AA}$ 
atelocollagen solutions (two samples for each experimental conditions) were diluted with $0.1 \mathrm{M} \mathrm{AA}$ 10 times to $0.3 \mathrm{mg} \cdot \mathrm{mL}^{-1}$. Then, the diluted solutions were transferred into quartz cells ( $2 \mathrm{~mm}$ path length) and measured by Jasco J-710 (Jasco, Tokyo, Japan) at a wavelength range between 190 and $350 \mathrm{~nm}$ at room temperature.

\subsection{Atelocollagen denaturation detection by electrophoresis}

The $0.3 \mathrm{mg} \cdot \mathrm{mL}^{-1}$ diluted solutions were mixed with assay buffer (Novex ${ }^{\circledR}$ Tris-Glycine SDS Sample Buffer 2X) following the manufacturer's instructions. Samples were analyzed by $1 \mathrm{D}$, sodium dodecylsulfate polyacrylamide gel electrophoresis (SDSPAGE, with an XCell4 SureLockTM Midi-Cell (Carlsband, CA, USA), at a constant voltage of $100 \mathrm{~V}$. Acrylamide gel SDS-PAGE NuPAGE ${ }^{\circledR}$ (Invitrogen, Carlsbad, CA, USA) Novex Tris-Acetate Gels $(3,8 \%)$ was used. Novex ${ }^{\circledR}$ Sharp Pre-Standard (Lifetechnologies, Carlsband, CA, USA) was the MW reference. The acrylamide gels were stained using a Comassie stain (Imperial Protein Stain, Thermo Scientific, Rockford, IL, USA). Gels were digitalized using a GEL LOGIC 200 (Kodak Scientific Imaging Systems, Rochester, NY, USA) imaging system.

\subsection{Scanning electron microscopy}

Atelocollagen powder in water $\left(3 \mathrm{mg} \cdot \mathrm{mL}^{-1}\right)$ was dissolved in $\mathrm{CO}_{2}$ atmosphere $(0.5 \mathrm{MPa})$ for two days, depressurized, transferred into petri dishes and covered by $1 \mathrm{mM}$ of $\mathrm{NaOH}$ ( $\mathrm{pH} 9.0$ ) overnight. The formed gel was fixed in 1-ethyl-3-(3-dimethylaminopropyl) carbodiimide/N-Hydroxysuccinimide (EDC/ NHS), dehydrated in graded ethanol solutions and critical-point dried (CPD 030, Bal-Tec). Finally, dried gels were gold coated $(6 \mathrm{~nm})$ and observed with a scanning electron microscope at $7 \mathrm{kV}$ (Tescan Mira3, Czech Republic). The mean fiber and pore diameters were calculated from 100 manual measurements using Fiji software [28].

\subsection{Transmission electron microscopy}

$\mathrm{CO}_{2}$ samples for TEM were cast as for SEM. The control sample was cast according to section 2.2. For the sectioned method [29], atelocollagen solutions were pipetted into $1 \mathrm{mM} \mathrm{NaOH}$ solutions to form stable gels, and left overnight at room temperature. Gels were fixed by glutaraldehyde, then by osmium tetroxide, dehydrated in graded ethanol solutions, converted to acetone and fixed in Durcupan ${ }^{\circledR}$ (SigmaAldrich, St. Louis, Missouri, USA). Fixed samples were sectioned by ultramicrotome (Leica EM UC6, Wetzlar, Germany) to $50 \mathrm{~nm}$ slices and negatively stained by lead nitrate.

\subsection{Rheology}

Continuous flow experiments were performed in cone-plate geometry on both $\mathrm{CO}_{2}$ and AA dissolved atelocollagen solutions by using an Anton Paar Physica MCR 301 Rheometer, connected to a Lauda RE 204 cooling thermostat $\left(4^{\circ} \mathrm{C}\right)$ and to a Peltier HPTD200 cell for heating. Methodology was adopted from Gobeaux et al. [30]. Measurements were done at shear rates between 0.001 and $400 \mathrm{~s}^{-1}$ at $4{ }^{\circ} \mathrm{C}$ without pre-shearing. Oscillatory experiments to observe gel formation kinetics ([31]) were performed using a TA Ares G2 Rheometer, with a Peltier cooling cell and cone-plate geometry. Samples were prepared according to Table 1.

The control atelocollagen sample was prepared according to section 2.2 at $1.5 \mathrm{mg} \cdot \mathrm{mL}^{-1}$ [9]. Pre shear at $2 \mathrm{rad} \cdot \mathrm{s}^{-1}$ for $10 \mathrm{~s}$ was performed prior to oscillation. Time sweep oscillation was performed at $1 \mathrm{~Hz}$, $0.8 \%$ strain.

Table 1. $\mathrm{CO}_{2}$ samples used in the rheological oscillatory experiments

\begin{tabular}{|c|c|c|c|c|c|c|c|c|}
\hline \multirow[t]{2}{*}{ Sample } & \multicolumn{5}{|c|}{ Dissolution conditions } & \multicolumn{3}{|c|}{ Rheometer conditions } \\
\hline & $\begin{array}{c}\text { concentration } \\
{\left[\mathrm{mg} \cdot \mathrm{mL}^{-1}\right]}\end{array}$ & $\begin{array}{c}\text { pressure } \\
{[\mathrm{MPa}]}\end{array}$ & $\begin{array}{c}\text { temperature } \\
{\left[{ }^{\circ} \mathrm{C}\right]}\end{array}$ & $\begin{array}{c}\text { duration } \\
\text { [days] }\end{array}$ & $\begin{array}{c}\text { depressurized } \\
\text { overnight }\end{array}$ & $\begin{array}{c}\text { dilution 1:1 } \\
\text { by } 1 \mathrm{mM} \\
\mathrm{NaOH} \text { on } \\
\text { rheometer }\end{array}$ & $\begin{array}{c}\text { final } \\
\text { concentration } \\
{\left[\mathrm{mg} \cdot \mathbf{m L}^{-1}\right]}\end{array}$ & $\begin{array}{c}\text { heated on } \\
\text { rheometer } \\
\text { geometry } \\
{\left[{ }^{\circ} \mathrm{C}\right]}\end{array}$ \\
\hline $\mathrm{CO}_{2} 0.5 \mathrm{MPa} 37^{\circ} \mathrm{C}$ & 1.5 & 0.5 & 4 & 2 & Yes & - & 1.5 & 37 \\
\hline $\mathrm{CO}_{2} 0.5 \mathrm{MPa} 37^{\circ} \mathrm{C} \mathrm{NaOH}$ & 3.0 & 0.5 & 4 & 2 & - & Yes & 1.5 & 37 \\
\hline $\mathrm{CO}_{2} 0.1 \mathrm{MPa} 4^{\circ} \mathrm{C}$ & 1.5 & 0.1 & 4 & 2 & Yes & - & 1.5 & 4 \\
\hline $\mathrm{CO}_{2} 0.5 \mathrm{MPa} 4{ }^{\circ} \mathrm{C}$ & 1.5 & 0.5 & 4 & 2 & Yes & - & 1.5 & 37 \\
\hline Control & $\begin{array}{l}\text { Purecol as supp } \\
\mathrm{NaOH}\end{array}$ & lied (in 0.0 & $01 \mathrm{M} \mathrm{HCL}, 4^{\circ} \mathrm{C}$ & C) neutraliz & zed by PBS and & - & 1.5 & 37 \\
\hline
\end{tabular}




\subsection{Light transmittance}

Samples prepared according to Table $1(0.5 \mathrm{MPa}$ $\mathrm{CO}_{2} 37^{\circ} \mathrm{C}$ and control sample), before heating, were pipetted into a $2 \mathrm{~mm}$ cuvette and heated to $37^{\circ} \mathrm{C}$ by a Peltier cell in a Jasco-J1500 CD spectrophotometer (Jasco, Tokyo, Japan). The transmittance values were read one hour after heating, at 310 and $550 \mathrm{~nm}$ [32].

\section{Results and discussion}

This study evaluated the solubility, gelation and gel structural properties of bovine type I atelocollagen processed by pressurized carbon dioxide in water. Atelocollagen processed in standard conditions in acetic acid solution was used for comparison. An increase of $\mathrm{CO}_{2}$ solubilized in water results in an increased carbonic acid content that lowers solution $\mathrm{pH}$. This principle was previously investigated to process various proteins including soy protein [33], insulin [34] and silk fibroin [35, 36].

\subsection{Effect of $\mathrm{CO}_{2}$ pressure and $\mathrm{pH}$ on atelocollagen self-assembly}

The gelation degree of atelocollagen solutions was measured by varying the $\mathrm{pH}$ of solution in $\mathrm{AA}(\mathrm{pH}=$ 3 ) and step-by-step neutralized by adding $\mathrm{NaOH}$. Summarizing the results in a plot (Figure 3a) it is possible to evidence that collagen precipitation and gelation start when $\mathrm{pH}$ is higher than 4. Similar $\mathrm{pH}$ conditions were obtained applying $0.9 \mathrm{MPa} \mathrm{CO}_{2}$ pressurized atmosphere for two days to an atelocollagen solution $\left(3 \mathrm{mg} \cdot \mathrm{mL}^{-1}\right)$. In this case, immediately after depressurization, the measured $\mathrm{pH}$ was equal to 3.2, thus compatible with the condition of dissolved collagen. The increase of $\mathrm{pH}$ necessary to obtain solution gelation is simply a function of time (up to 5.7 after $70 \mathrm{~min}$ ), and is due to the gas evolution from the solution (Figure $3 \mathrm{~b}$ ). The dissolution effect seems to be correlated with the $\mathrm{CO}_{2}$ pressureinduced drop of $\mathrm{pH}$, since the use of an inert gas pressurization like $\mathrm{N}_{2}$ does not allow solubilisation.

\subsection{Atelocollagen dissolution kinetics}

Swelling and dissolution behaviours of atelocollagen powders were first qualitatively recorded in different solvents (AA $0.5 \mathrm{M}, \mathrm{H}_{2} \mathrm{O}$ and $0.9 \mathrm{MPa} \mathrm{CO}$ ) by using a camera. Digital images were collected immediately after mixing the atelocollagen powder with solvents at predetermined time intervals. For the $0.9 \mathrm{MPa}$ $\mathrm{CO}_{2}$ sample, images one minute before pressurization were also acquired.

The higher the $\mathrm{CO}_{2}$ pressure, the faster the dissolution of atelocollagen in the solutions was observed. In the $\mathrm{H}_{2} \mathrm{O}$ and $\mathrm{AA} 0.5 \mathrm{M}$ samples, bubbles remained attached to atelocollagen powder (Figure 4 upper and center line, time 0-60 min), reducing the atelocollagen-solvent contact. Pressurization by $\mathrm{CO}_{2}$ allows bubbles compression, improving the solvent-atelocollagen contact and contributing to the atelocollagen dissolution (Figure 4 bottom, time 0-10 min).

The dissolved atelocollagen in AA $0.1 \mathrm{M}, \mathrm{AA} 0.5 \mathrm{M}$, $0.5 \mathrm{MPa} \mathrm{CO}$, and $0.9 \mathrm{MPa} \mathrm{CO}_{2}$ at defined time points was quantified by microBCA ${ }^{\circledR}$ assays (Figure 5b). Taking the dissolution in AA $0.5 \mathrm{M}$ after 2 hours, as a reference of $100 \%$ dissolution, about $140 \%$ of atelocollagen was dissolved in 0.5 or $0.9 \mathrm{MPa} \mathrm{CO}$ and only $75 \%$ in $0.1 \mathrm{M} \mathrm{AA}$.

Even if equilibrium $\mathrm{pH}$ of $\mathrm{CO}_{2}$ samples under pressure was not measurable, by the way, right after

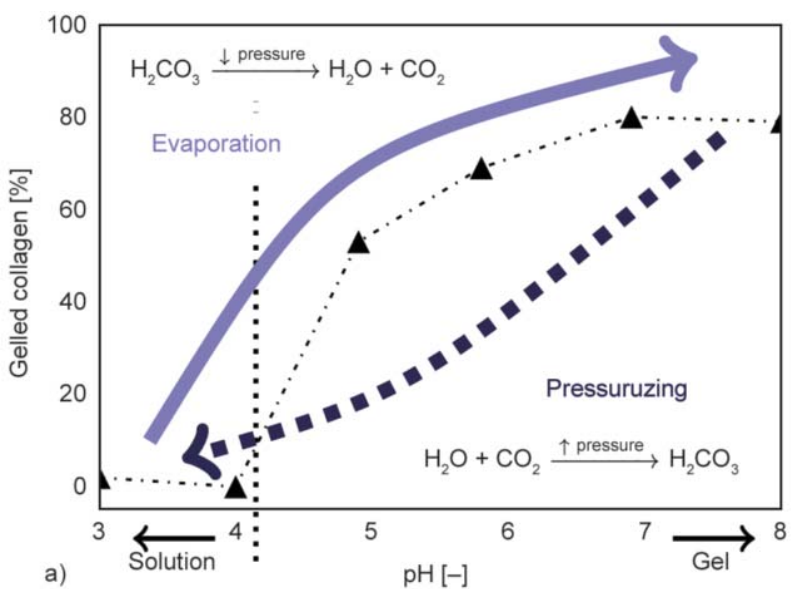

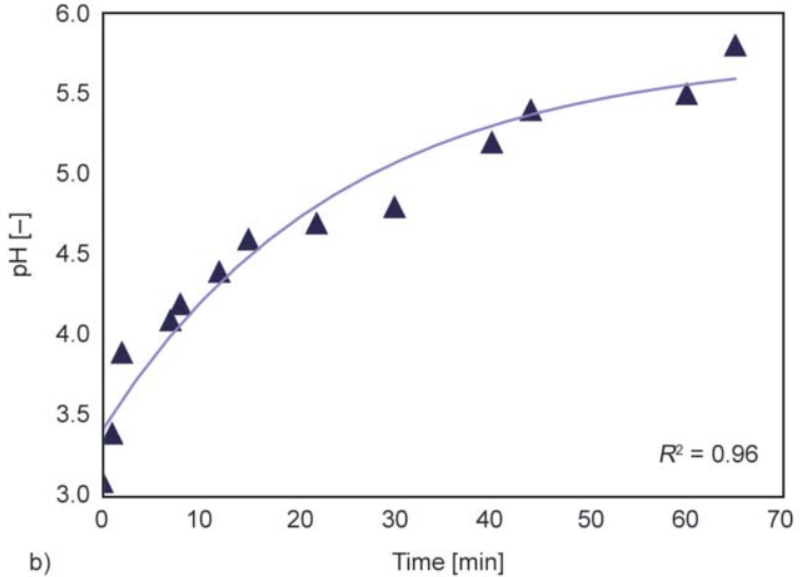

Figure 3. a) Principle of $\mathrm{CO}_{2}$ processing. Dissolution by pressurizing and gelation by evaporation (depressurizing), neutralized AA-atelocollagen solutions were used for construction of dashed curve, b) depressurization of atelocollagencarbonic acid solution $\left(\mathrm{CO}_{2} 0.9 \mathrm{MPa}\right)$ causes $\mathrm{CO}_{2}$ gas evolution and consequent increase of $\mathrm{pH}$. 


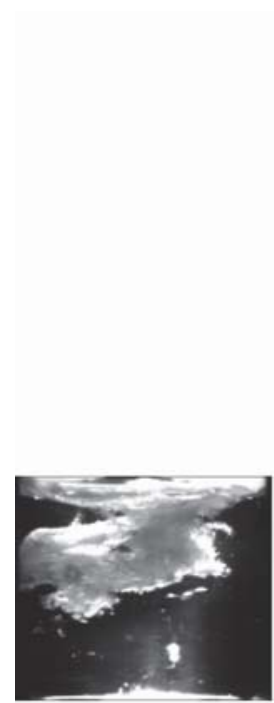

$-1$
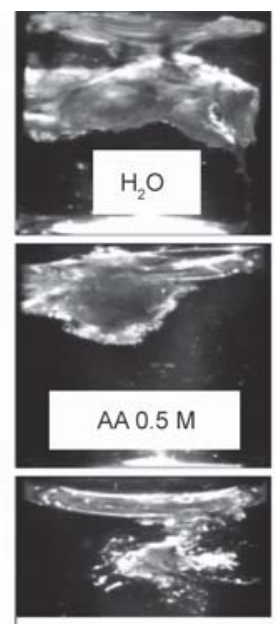

$\mathrm{CO}_{2} 0.9 \mathrm{MPa}$
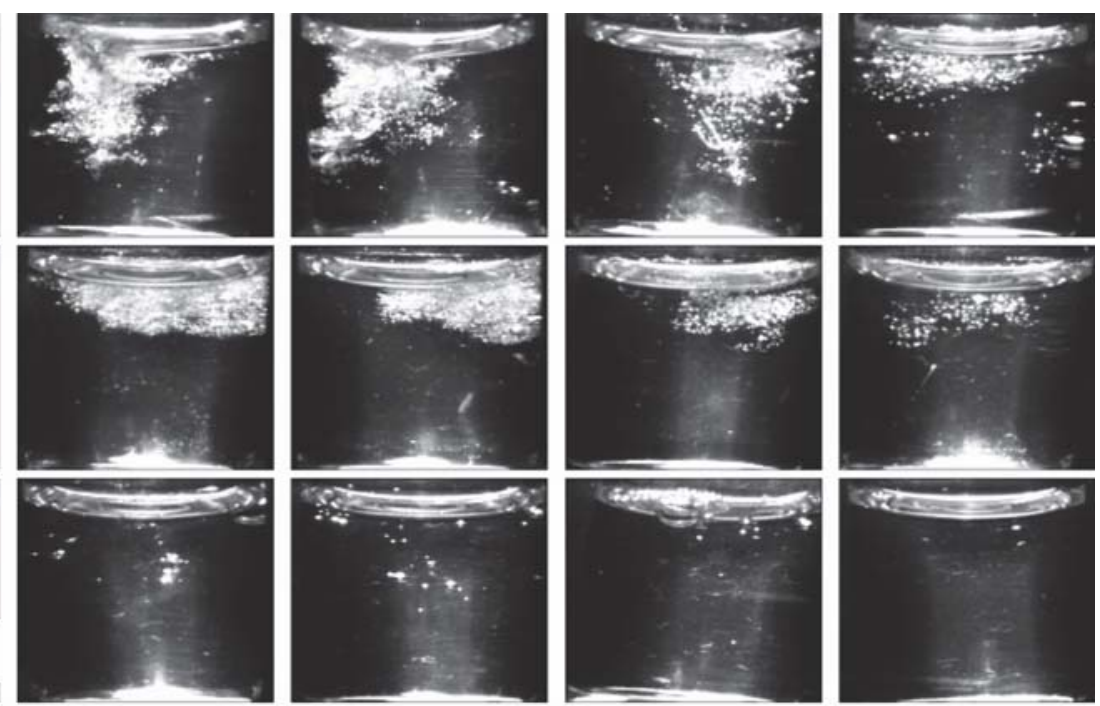

5

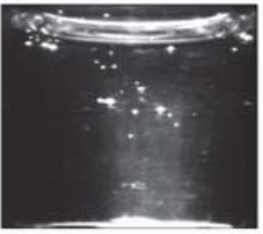

10

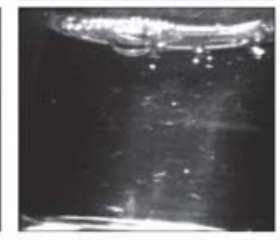

30

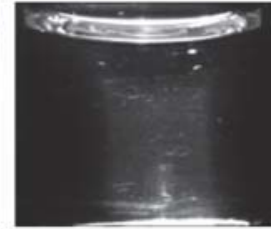

$60 \mathrm{~min}$

Figure 4. Dissolution of atelocollagen in water, AA $0.5 \mathrm{M}$ solution and $\mathrm{CO}_{2}$ athmosphere at $0.9 \mathrm{MPa}$ observed by camera

depressurization was equal to $\mathrm{pH} 3.2$ acquired at atmospheric pressure (Figure $3 \mathrm{~b}$ ). Then effect of $\mathrm{pH}$ on the dissolution cannot be directly discussed. However it seems the improved solvent-atelocollagen contact (due compression of bubbles surrounding atelocollagen powder, Figure 4) is the major effect improving the speed of dissolution of $\mathrm{CO}_{2}$ samples. The effect was even improved by the fact, that the samples were repeatedly pressurized and depressurized during the experiment, causing the reduction of bubbles number and size and, thus better solvent-atelocollagen interaction, as can be seen in the time sequence of Figure 4.

\subsection{Stability of atelocollagen within $\mathrm{AA}$ and $\mathrm{CO}_{2}$ dissolution}

Atelocollagen stability in samples AA $0.1 \mathrm{M}$, AA $0.5 \mathrm{M}, 0.5 \mathrm{MPa} \mathrm{CO}_{2}$, and $0.9 \mathrm{MPa} \mathrm{CO}_{2}$ was evaluated by both SDS-PAGE (Figure 6a) and CD spectroscopy

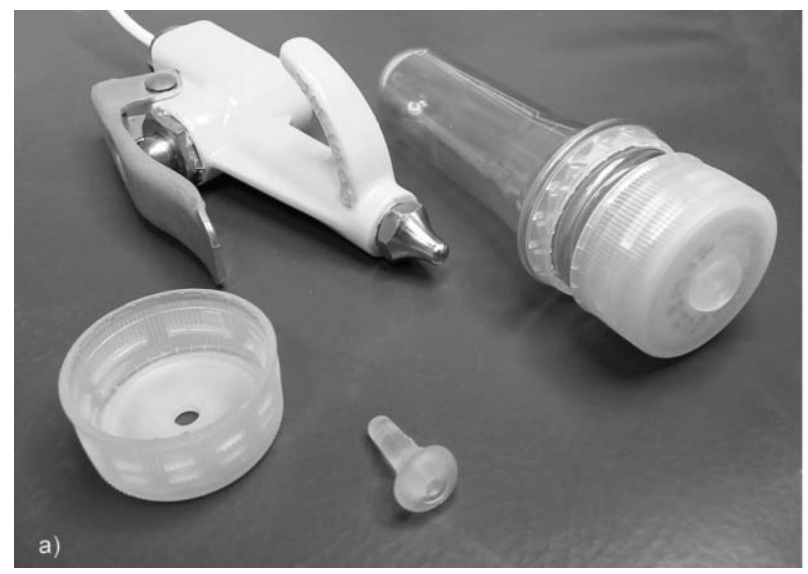

(Figure 6b) after 2, 4, and 6 days, respectively. CD signals at $221.5 \mathrm{~nm}$ were normalized and converted to percentage where the maximum at 2, 4 and 6 days for each solvent was set as $100 \%$. Small variation in signals is probably induced by pipetting error rather than denaturation. We did not find any significant differences between individual samples, both with SDS-PAGE and CD spectroscopy. These results indicate that denaturation did not occur in any of the tested samples.

\subsection{Rheological behaviour of atelocollagen in both $\mathrm{AA}$ and $\mathrm{CO}_{2}$ water solutions}

The viscosity of AA $0.1 \mathrm{M}$ and $\mathrm{CO}_{2} 0.5 \mathrm{MPa}$ samples was determined by continuous flow rheological analysis. The atelocollagen sample prepared in $0.1 \mathrm{M} \mathrm{AA}$ did not show any $\mathrm{pH}$ changes during the measurement $(\mathrm{pH}=3.0)$, while the $\mathrm{pH}$ of the $0.5 \mathrm{MPa} \mathrm{CO} 2$ increased during the measurement from 3.8 to 4.3 , due

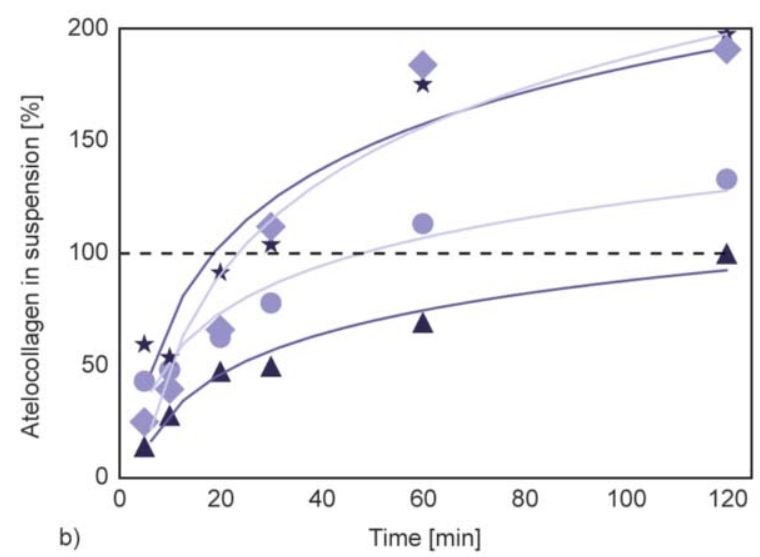

Figure 5. a) Pressurizable polypropylene bottles, cups, valves and dispenser used in the experiments, b) atelocollagen dry powder dissolution kinetics - AA 0.1 M (triangles), AA 0.5 M (circles), $\mathrm{CO}_{2} 0.5 \mathrm{MPa}$ (stars), $\mathrm{CO}_{2} 0.9 \mathrm{MPa}$ (diamonds). 

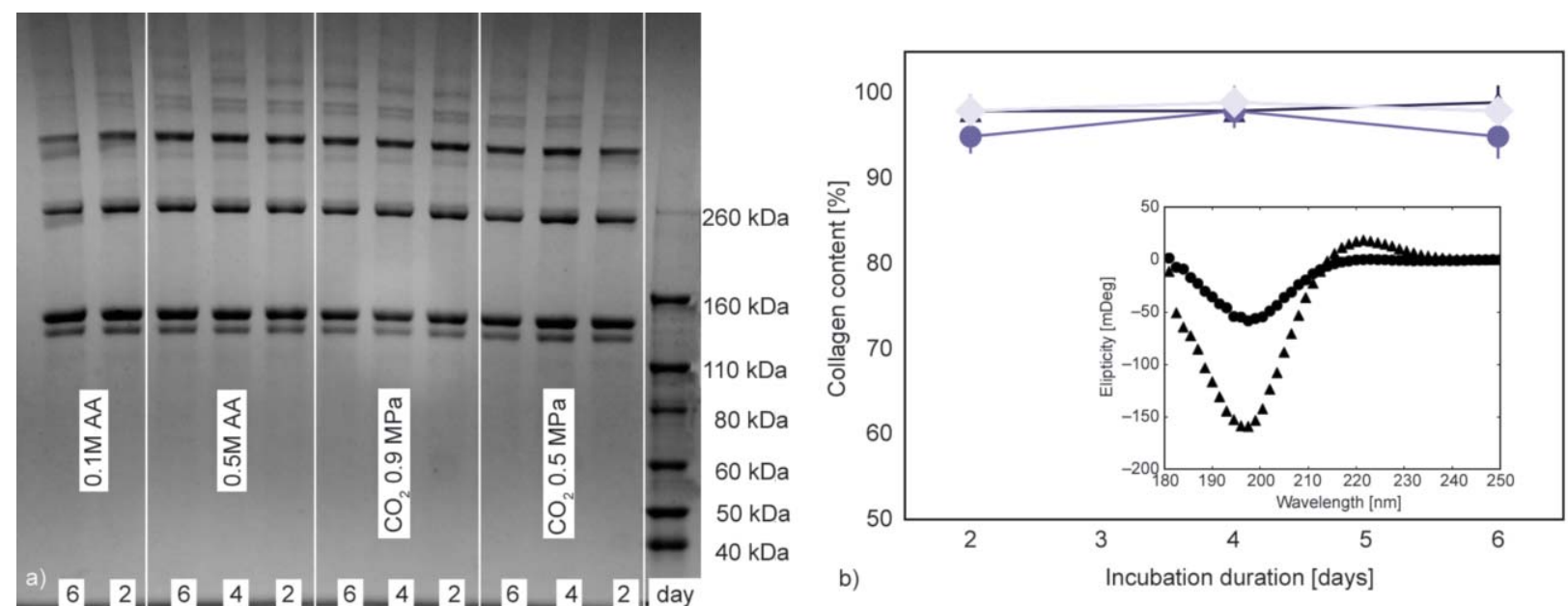

Figure 6. A SDS-PAGE (a) and CD spectroscopy (b) do not detect any atelocollagen denaturation in $\mathrm{CO}_{2}$ solvents. $\mathrm{CO}_{2}$ $0.5 \mathrm{MPa}$ (triangles), $\mathrm{CO}_{2} 0.9 \mathrm{MPa}$ (circles), 0.1 M AA (stars), 0.5 M AA (diamonds). Overlay shows CD spectrum of atelocollagen (triangle) and gelatin (circle).

to $\mathrm{CO}_{2}$ gas evolution from the solution. This inconvenience cannot be avoided, since it is impossible to perform the viscosity measurements under constant pressurized conditions. Much more intensive gas evolution of $\mathrm{CO}_{2} 0.9 \mathrm{MPa}$ samples resulted in escaping of part of the sample out of the rheometer geometry, so the measurements were excluded from the results. $\mathrm{CO}_{2} 0.1 \mathrm{MPa}$ samples were not measurable because of evidence of incomplete dissolution, containing few millimetre sized atelocollagen aggregates.

Results showed (Figure 7a and 7b) clear differences between viscosities of AA $0.1 \mathrm{M}$ (triangles) and $0.5 \mathrm{MPa} \mathrm{CO} 2$ (circles) samples. Intrinsic viscosity was calculated using regression of reduced viscosity to the zero concentration (Figure 7b) [30]. The obtained intrinsic viscosity value for $0.1 \mathrm{M} \mathrm{AA}([\eta]=$ $602)$ is lower than previously reported, while $[\eta]=$ 764 for the $\mathrm{CO}_{2}$ sample is in good agreement with the value found in literature [30]. The difference also correlates well with the atelocollagen self-assembly curve obtained in Figure 3a. Prolonged (16 h) continuous flow measurements (Figure 7c) of a depressurized $0.5 \mathrm{MPa} \mathrm{CO}$ sample showed increased viscosity from 14 to $110 \mathrm{~Pa} \cdot \mathrm{s}$ as a consequence of carbon dioxide loss from the solution at atmospheric pressure.

Gelation kinetics was evaluated by using oscillatory rheological analysis, on samples prepared according to Table 1. $G^{\prime \prime}$ and $G^{\prime}$ (storage and loss modulus respectively) are representative of the viscous and elastic behaviour of a material. A larger value of $G^{\prime}$ in comparison to $G^{\prime \prime}$ indicates that a material displays predominantly elastic properties, while $G^{\prime \prime}>G^{\prime}$ indicates that viscous properties prevail.

The experimental curves are reported in Figure 8, while the synthesis of the solutions properties at different times (the beginning, the first gelation plateau, and at the end) are provided in Table 2.
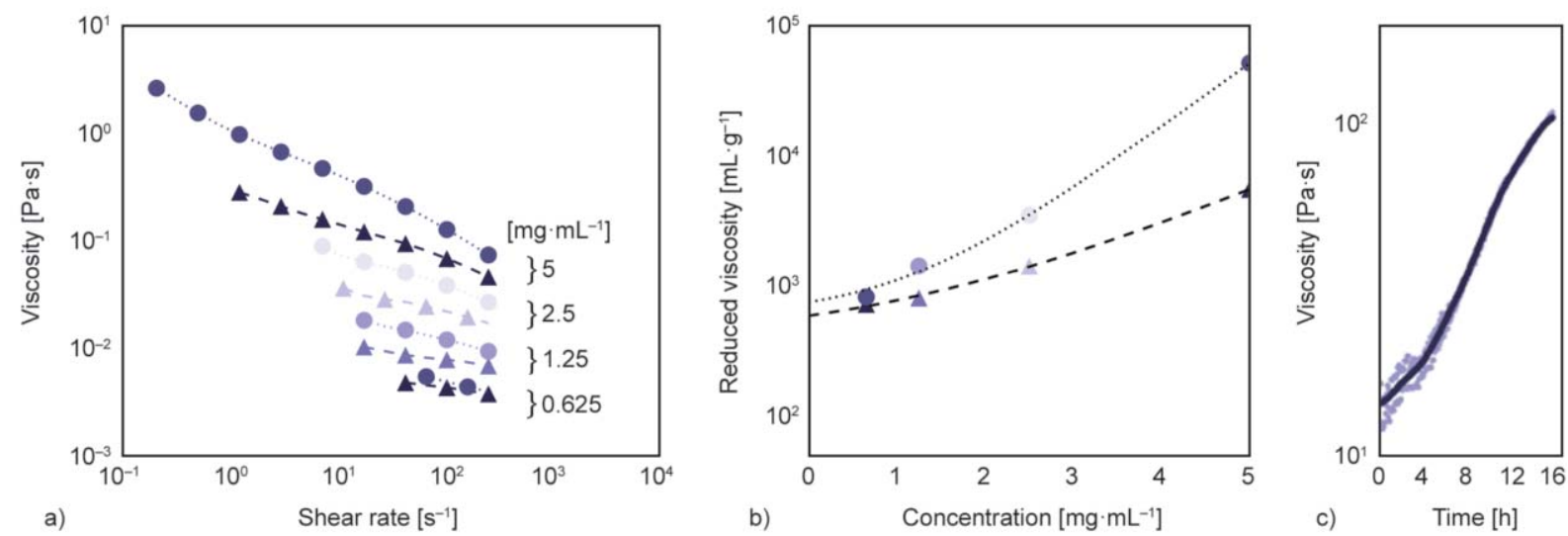

Figure 7. a) Continuous flow rheometry of atelocollagen dissolved in $0.1 \mathrm{MAA}$ (triangles) and in $0.5 \mathrm{MPa} \mathrm{CO}_{2}$ (circles), b) reduced viscosity against atelocollagen concentration. c) Slow increase of viscosity of depressurized atelocollagen- $\mathrm{CO}_{2}$ solution at $4^{\circ} \mathrm{C}$ in 16 hours. 

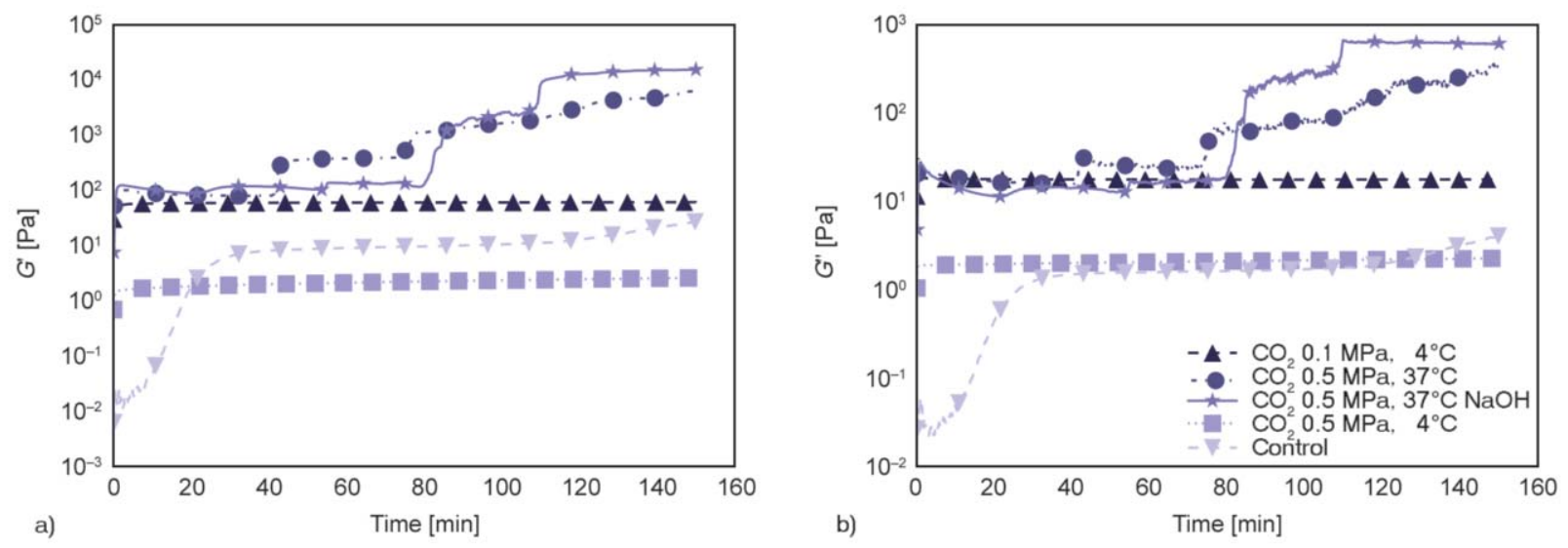

Figure 8. Viscoelastic properties development during atelocollagen self-assembly. a) Storage modulus, b) loss modulus. The samples were prepared according to Table 1 .

The samples depressurized overnight $\left(0.5 \mathrm{MPa} \mathrm{CO}_{2}\right.$ $4^{\circ} \mathrm{C}$ and $0.5 \mathrm{MPa} \mathrm{CO} 37^{\circ} \mathrm{C}$ ) were prepared identically (Table 1). The cooled $0.5 \mathrm{MPa} \mathrm{CO} 4^{\circ} \mathrm{C}$ samples were liquid at the beginning of the experiment (Table $2, \tan \delta=1.5$ ), however they became weak gels $(\tan \delta=0.9)$ by the end of the experiment, probably due to manipulation, pre-shear, and rheometer vibrations which induced release of $\mathrm{CO}_{2}$. The $0.5 \mathrm{MPa}$ $\mathrm{CO}_{2} 37^{\circ} \mathrm{C}$ sample became a gel within $0.6 \mathrm{~min}(\tan \delta=$ 0.4). Similarly, $0.5 \mathrm{MPa} \mathrm{CO}_{2} 37^{\circ} \mathrm{C} \mathrm{NaOH}$, formed a gel very quickly $(\tan \delta=0.2$ at $1.3 \mathrm{~min})$, despite the lack of overnight depressurization (Table 1). $\mathrm{CO}_{2}$ $0.9 \mathrm{MPa}$ samples had similar results to $\mathrm{CO}_{2} 0.5 \mathrm{MPa}$ (Table 1), so they were not shown in the graphs. $\mathrm{CO}_{2}$ 0.1 MPa sample was used as a demonstration of insufficient dissolution pressure conditions. This result is in contrast with similar Tanaka et al. [22] experiment, who reported good dissolution and processing of fish-derived soluble collagen at atmospheric pressure $(0.1 \mathrm{MPa})$ of carbon dioxide. Probably different collagen source material is responsible for this inconsistency.

All samples displayed large increases of $G^{\prime}$ and a decreases of $\tan \delta$, for the atelocollagen dissolved in $0.5 \mathrm{MPa} \mathrm{CO}$ heated at $37^{\circ} \mathrm{C}$. $G^{\prime}$ for $0.5 \mathrm{MPa} \mathrm{CO}$ and $0.5 \mathrm{MPa} \mathrm{CO}_{2} \mathrm{NaOH}$ treated and kept at $37^{\circ} \mathrm{C}$ reached plateau levels equal to about 6200 and $15000 \mathrm{~Pa} \cdot \mathrm{s}$ respectively, by the end of the test, thus indicating further and progressive assembling of the gel.

Attempts to heat up $\mathrm{CO}_{2}$ samples to $37{ }^{\circ} \mathrm{C}$ immediately after depressurization failed. While $G^{\prime}$ raised to higher values for a short time, after few minutes it dropped down to low values, indicating denaturation of the collagen. This can be explained by the fact that $\mathrm{pH}$ was not enough close to neutrality. To prevent denaturation after heating as well as to keep the samples solubilized prior rheometer experiment depressurization procedure was applied overnight.

The gelation kinetics is much faster for $\mathrm{CO}_{2}$ samples. The faster kinetics of $\mathrm{CO}_{2}$ samples seems to be connected with the fact that the solutions cooled and depressurized of $\mathrm{CO}_{2}$ overnight (Figure $8 \mathrm{a}, 8 \mathrm{~b} 0.5 \mathrm{MPa}$ $\mathrm{CO}_{2} 4^{\circ} \mathrm{C}, 0.5 \mathrm{MPa} \mathrm{CO}_{2} 37^{\circ} \mathrm{C}$ ) have a $\mathrm{pH}$ of $4.0-4.5$ (Table 2), which is already at the border of the atelocollagen gelling region (Figure $3 \mathrm{a}$ ) and relatively close to its isoelectric point (assumed to be 7.4, but generally between 5-9 depending on type and amount of salts [37]). Thus, part of the atelocollagen molecules interact, have a lower $\tan \delta$ (Figure 8 , Table 2 ), and these act as nucleation sites, consequently greatly reducing gelation times [8].

Table 2. Viscoelastic properties development during atelocollagen self-assembly. The samples were prepared according to Table 1.

\begin{tabular}{|c|c|c|c|c|c|c|c|c|c|c|c|c|c|}
\hline \multirow[t]{2}{*}{ Sample } & \multicolumn{5}{|c|}{ Initial solution properties } & \multicolumn{4}{|c|}{ First gelation plateau } & \multicolumn{4}{|c|}{ Final gel properties } \\
\hline & pH & $\begin{array}{l}\text { time } \\
\text { [min] }\end{array}$ & $\begin{array}{c}G^{\prime} \\
{[\mathrm{Pa} \cdot \mathbf{s}]}\end{array}$ & $\begin{array}{c}G^{\prime \prime} \\
{[\mathrm{Pa} \cdot \mathrm{s}]}\end{array}$ & $\begin{array}{c}\tan \delta \\
{[-]}\end{array}$ & $\begin{array}{l}\text { time } \\
{[\mathrm{min}]}\end{array}$ & $\begin{array}{c}G^{\prime} \\
{[\mathrm{Pa} \cdot \mathrm{s}]}\end{array}$ & $\begin{array}{c}G^{\prime \prime} \\
{[\mathrm{Pa} \cdot \mathrm{s}]}\end{array}$ & $\begin{array}{c}\tan \delta \\
{[-]}\end{array}$ & $\begin{array}{c}\text { time } \\
{[\mathrm{min}]}\end{array}$ & $\begin{array}{c}G^{\prime} \\
{[\mathrm{Pa} \cdot \mathbf{s}]}\end{array}$ & $\begin{array}{c}G^{\prime \prime} \\
{[\mathrm{Pa} \cdot \mathrm{s}]}\end{array}$ & $\begin{array}{c}\tan \delta \\
{[-]}\end{array}$ \\
\hline $\mathrm{CO}_{2} 0.5 \mathrm{MPa} 37^{\circ} \mathrm{C}$ & 4.4 & 0.3 & 52.1 & 20.5 & 0.4 & 0.6 & 90.6 & 32.9 & 0.4 & 150 & 6189.6 & 341.2 & 0.05 \\
\hline $\mathrm{CO}_{2} 0.5 \mathrm{MPa} 37^{\circ} \mathrm{C} \mathrm{NaOH}$ & 4.0 & 0.3 & 11.2 & 6.7 & 0.6 & 1.2 & 113.1 & 26.6 & 0.2 & 150 & 15094.0 & 605.5 & 0.04 \\
\hline $\mathrm{CO}_{2} 0.1 \mathrm{MPa} 4^{\circ} \mathrm{C}$ & 5.3 & 0.3 & 39.5 & 15.2 & 0.4 & 25.0 & 58.5 & 17.6 & 0.3 & 150 & 60.6 & 17.6 & 0.30 \\
\hline $\mathrm{CO}_{2} 0.5 \mathrm{MPa} 4{ }^{\circ} \mathrm{C}$ & 4.5 & 0.3 & 1.0 & 1.4 & 1.5 & - & - & - & - & 150 & 2.6 & 2.3 & 0.90 \\
\hline Control & 7.4 & 0.3 & 0.013 & 0.041 & 3.1 & 35.0 & 7.5 & 1.4 & 0.2 & 150 & 26.7 & 4.0 & 0.15 \\
\hline
\end{tabular}




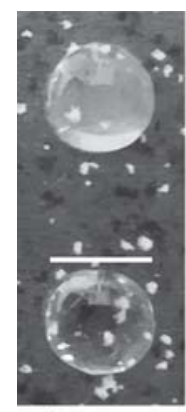

a)

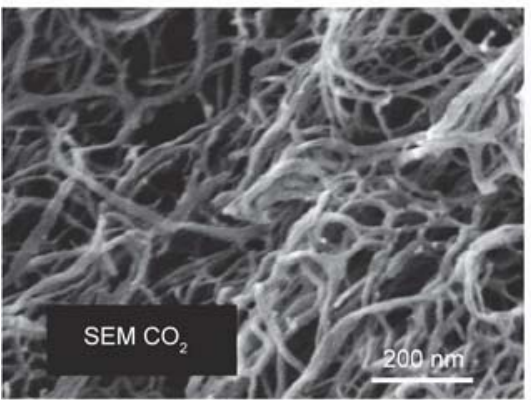

e)

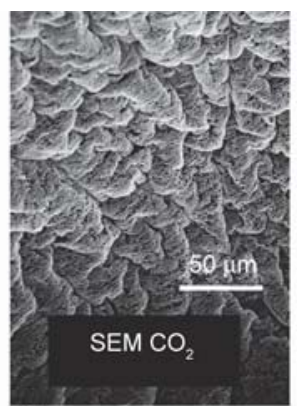

b)

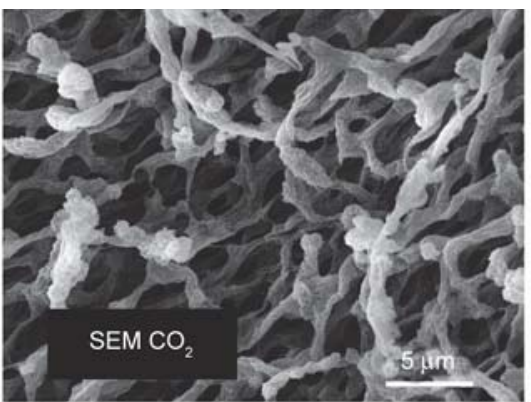

c)

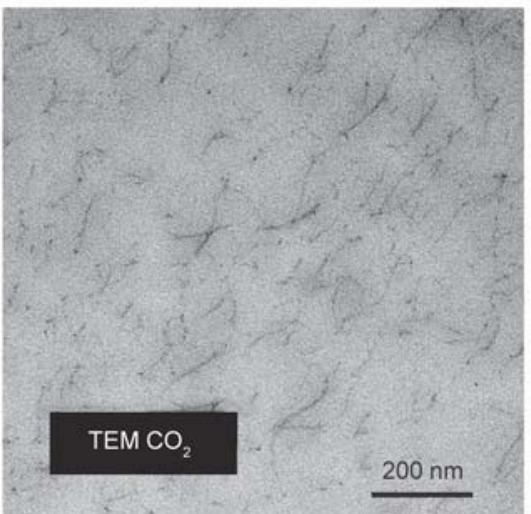

f)

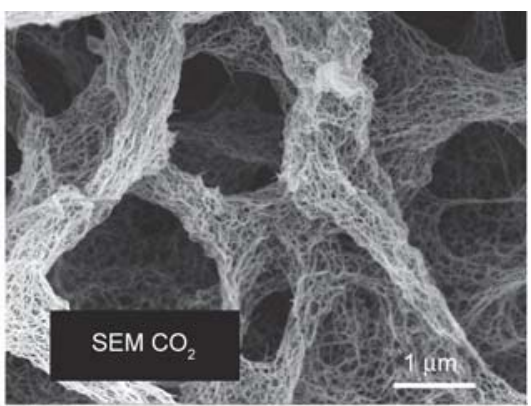

d)

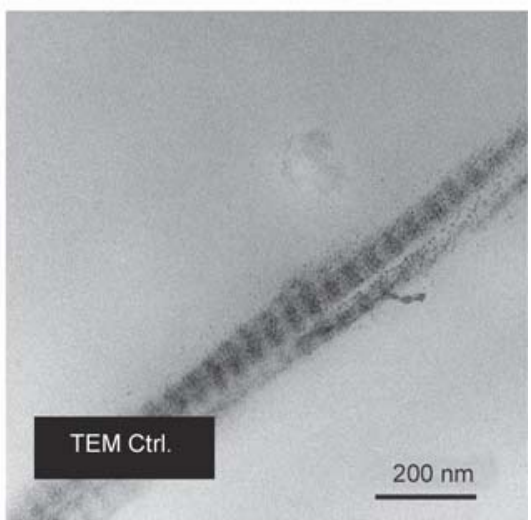

g)

Figure 9. Structural analysis of atelocollagen gels. $\mathrm{CO}_{2}$ and $\mathrm{Ctrl}$. (control) indicating sample preparation method. a) Macro view on gels - top control, bottom $\mathrm{CO}_{2}$ casting protocol, bar $4 \mathrm{~mm}$. b) Gel cross-section, c), d) gel surface, e) gel cross-section - high magnification (6 nm coating on both sites of fibers), f) $\left(\mathrm{CO}_{2}\right), \mathrm{g}$ ) TEM (control) sections.

The gelation kinetics of the sample produced as control (Figure 8, Table 2) is most probably down-regulated by the presence of ions (salts), which hinder functional groups of the atelocollagen monomers, thus lowering the probability of monomer-monomer interaction [9,31]. $\mathrm{CO}_{2}$ gels showed two fold higher modulus (Table 2, right) than gels produced as control, which is most probably connected to the presence of smaller diameter fibers size $(8.6 \pm 4 \mathrm{~nm}$ for $\mathrm{CO}_{2}$ samples versus $76 \pm 30 \mathrm{~nm}$ for control samples) and consequently higher number of network links (Figure 9, Table 3). The results are consistent with other works reported in literature [31,38].

The depressurization overnight helped us to work completely without additives during gelation, however, with the time the solution viscosity tend increase about one fold (Figure 7c). If this fact by one side could influence negatively the processability of the material, not using additives could represent a clear advantage.

\subsection{Structural analysis of gels}

The structure of self-assembled gels prepared by both the control and the $\mathrm{CO}_{2}$ protocol was characterized using camera (Figure 9a), SEM (Figure 9b9e), TEM (Figure 9f, 9g). The camera pictures (Figure 9a) showed clear differences in transparency between gels cast from the control solutions and from the $0.5 \mathrm{MPa} \mathrm{CO}_{2}$ solutions, also confirmed from UV/Vis spectroscopy data (Table 4). This transparency difference is evidently in correlation with the collagen fiber sizes.

Table 3. Quantification fiber diameter of atelocollagen gels

\begin{tabular}{|l|c|l|c|c|l|}
\hline Sample & Figure 9 label & $\begin{array}{c}\text { Imaging } \\
\text { method }\end{array}$ & $\begin{array}{c}\text { Fiber diameter } \\
{[\mathbf{n m}]}\end{array}$ & $\begin{array}{c}\text { Concentration } \\
{\left[\mathbf{m g} \cdot \mathbf{m L} \mathbf{L}^{-1}\right]}\end{array}$ & \multicolumn{1}{|c|}{ Note } \\
\hline $\mathrm{CO}_{2}$ & e) & SEM & $9.1 \pm 7$ & 3 & $\begin{array}{l}\text { Glutaraldehyde fixed, critical point dried, subtracted } \\
\text { coating 6 nm on both sites }\end{array}$ \\
\hline $\mathrm{CO}_{2}$ & f) & TEM sectioned & $8.1 \pm 2$ & 3 & $\begin{array}{l}\text { Fixed in epoxy, sectioned, osmium tetroxide, lead ni- } \\
\text { trate contrasting }\end{array}$ \\
\hline $\mathrm{CO}_{2}$ mean & - & - & $8.6 \pm 4$ & 3 & \\
\hline Control & g) & TEM sectioned & $76 \pm 30$ & 3 & $\begin{array}{l}\text { Fixed in epoxy, sectioned, osmium tetroxide, lead ni- } \\
\text { trate contrasting }\end{array}$ \\
\hline
\end{tabular}


Table 4. Quantification of transparency of collagen gels by UV spectroscopy. The samples were prepared according to Table 1.

\begin{tabular}{|l|c|c|}
\hline \multicolumn{1}{|c|}{ Sample } & $\begin{array}{c}\text { Transmittance } \\
\text { at } \mathbf{3 1 0} \mathbf{~ n m} \\
{[\mathbf{\%}]}\end{array}$ & $\begin{array}{c}\text { Transmittance } \\
\text { at } \mathbf{5 5 0} \mathbf{~ n m} \\
{[\mathbf{\%}]}\end{array}$ \\
\hline $\mathrm{CO}_{2} 0.5 \mathrm{MPa} 37^{\circ} \mathrm{C}$ & 99.3 & 99.7 \\
\hline Control & 79.3 & 95.5 \\
\hline
\end{tabular}

A previous work by Wood and Keech [9], reported atelocollagen gels formed by the control method (acidic solution neutralized by buffer and base) and described the formation of fibrils with a diameter of $3-15 \mathrm{~nm}$ in early stage of atelocollagen gel formation (up to $10 \mathrm{~min}$ from start of experiment). In later stages $(>20 \mathrm{~min})$ of gel formation, the initial fibers regrow/aggregate to larger D-banded fibers.

It seems the $\mathrm{CO}_{2}$ gels form similar thin fibers $(\varnothing=$ $8.6 \pm 4 \mathrm{~nm}$ ), but those fibers do not regrow to thicker fibers (Figure 9d and 9f). We believe, fibers made by $\mathrm{CO}_{2}$ protocol do not regrow into thicker ones due to a very fast nucleation phase ( $\tan \delta$ rises from 0.2 to 0.4 in one minute). The same $\tan \delta$ for control samples was obtained after 30 minutes. Therefore the control gel sample had about $20 \times$ longer time for fiber assembly. In other words, faster gelation (by $\mathrm{CO}_{2}$ protocol) resulted in formation of fibers that were thinner that those produced by slower gelation (control). This is in agreement with common crystallization kinetics [39].

However, the surface morphology of the gels (Figure 9c and 9d) is different with respect to the bulk (cross-section in Figure 9e). Where the surface of the gel is in direct contact with the incubation buffer (pH 9.0) the structuring of the material is not homogenous: pores and traces of larger fibres are present, but the assembly process seems incomplete. This effect could be explained with a slowing down of the recombination process due to the direct contact with the buffer solution.

\section{Conclusions}

Pressurized carbon dioxide/water solutions dissolved atelocollagen well without inducing any denaturation effect. Gels can be easily formed by removing pressure, due to gas evolution of $\mathrm{CO}_{2}$ from the solutions and by the corresponding increase in the $\mathrm{pH}$. Gels obtained with this method have smaller size of fibrils and higher rheological modules properties compared to the gels obtained from AA solutions and
$\mathrm{NaOH}$ neutralization. This dissolution and gelation method is quite versatile, and doesn't require harmful chemicals, thus opening potential applications in various fields including tissue engineering. Medical applications, where absence of contaminants, adjustable rheological properties and transparency (e.g., cornea) are required, can particularly be envisioned.

\section{Acknowledgements}

The results of this research were obtained under the CEITEC project in 2020 (LQ1601) with the financial support of the Ministry of Education, Youth and Sports of the Czech Republic as part of targeted support from the National Programme II sustainability, moreover project was partially supported by LQ1605 (MEYS CR, NPU II) and CARITRO Foundation (CARITRO-2015 Cellularized 3D-Building Blocks).

\section{References}

[1] Abou Neel E. A., Bozec L., Knowles J. C., Syed O., Mudera V., Day R., Hyun J. K.: Collagen - Emerging collagen based therapies hit the patient. Advanced Drug Delivery Reviews, 65, 429-456 (2013). https://doi.org/10.1016/j.addr.2012.08.010

[2] Moore M. A., Samsell B., Wallis G., Triplett S., Chen S., Jones A. L., Qin X.: Decellularization of human dermis using non-denaturing anionic detergent and endonuclease: A review. Cell and Tissue Banking, 16, 249-259 (2015). https://doi.org/10.1007/s10561-014-9467-4

[3] Chern P. L., Baum C. L., Arpey C. J.: Biologic dressings: Current applications and limitations in dermatologic surgery. Dermatologic Surgery, 35, 891-906 (2009). https://doi.org/10.1111/j.1524-4725.2009.01153.x

[4] Cheung H. S.: Distribution of Type I, II, III and V in the pepsin solubilized collagens in bovine menisci. Connective Tissue Research, 16, 343-356 (1987). https://doi.org/10.3109/03008208709005619

[5] Bowes J. H., Elliott R. G., Moss J. A.: The composition of collagen and acid-soluble collagen of bovine skin. Biochemical Journal, 61, 143-150 (1955).

[6] Miyata T., Taira T., Noishiki Y.: Collagen engineering for biomaterial use. Clinical Materials, 9, 139-148 (1992). https://doi.org/10.1016/0267-6605(92)90093-9

[7] Sato K., Ebihara T., Adachi E., Kawashima S., Hattori S., Irie S.: Possible involvement of aminotelopeptide in self-assembly and thermal stability of collagen I as revealed by its removal with proteases. Journal of Biological Chemistry, 275, 25870-25875 (2000). https://doi.org/10.1074/jbc.M003700200

[8] Na G. C., Butz L. J., Carroll R. J.: Mechanism of in vitro collagen fibril assembly. Kinetic and morphological studies. Journal of Biological Chemistry, 261, 12290-12299 (1986). 
[9] Wood G. C., Keech M. K.: The formation of fibrils from collagen solutions 1 . The effect of experimental conditions: Kinetic and electron-microscope studies. The Biochemical journal, 75, 588-598 (1960).

https://doi.org/10.1042/bj0750588

[10] Liu X., Dan N., Dan W.: Insight into the collagen assembly in the presence of lysine and glutamic acid: An in vitro study. Materials Science and Engineering: C, 70, 689-700 (2017). https://doi.org/10.1016/j.msec.2016.09.037

[11] Vulpe R., Le Cerf D., Dulong V., Popa M., Peptu C., Verestiuc L., Picton L.: Rheological study of in-situ crosslinkable hydrogels based on hyaluronanic acid, collagen and sericin. Materials Science and Engineering: C, 69, 388-397 (2016).

https://doi.org/10.1016/j.msec.2016.07.003

[12] Silver F. H., Trelstad R. L.: Type I collagen in solution. Structure and properties of fibril fragments. Journal of Biological Chemistry, 255, 9427-9433 (1980).

[13] Hofman K., Tucker N., Stanger J., Staiger M., Marshall S., Hall B.: Effects of the molecular format of collagen on characteristics of electrospun fibres. Journal of Materials Science, 47, 1148-1155 (2012). https://doi.org/10.1007/s10853-011-5775-2

[14] Pal G. K., Suresh P. V.: Comparative assessment of physico-chemical characteristics and fibril formation capacity of thermostable carp scales collagen. Materials Science and Engineering: C, 70, 32-40 (2017). https://doi.org/10.1016/j.msec.2016.08.047

[15] Duan Z., Sun R., Zhu C., Chou I-M.: An improved model for the calculation of $\mathrm{CO} 2$ solubility in aqueous solutions containing $\mathrm{Na}^{+}, \mathrm{K}^{+}, \mathrm{Ca}^{2+}, \mathrm{Mg}^{2+}, \mathrm{Cl}^{-}$, and $\mathrm{SO}_{4}{ }^{2-}$. Marine Chemistry, 98, 131-139 (2006).

https://doi.org/10.1016/j.marchem.2005.09.001

[16] Silva J. C., Barros A. A., Aroso I. M., Fassini D., Silva T. H., Reis R. L., Duarte A. R. C.: Extraction of collagen/ gelatin from the marine demosponge Chondrosia reniformis (Nardo, 1847) using water acidified with carbon dioxide - process optimization. Industrial and Engineering Chemistry Research, 55, 6922-6930 (2016). https://doi.org/10.1021/acs.iecr.6b00523

[17] Chaschin I. S., Grigoriev T. E., Bakuleva N. P., Abramchyk S. S., Nikitin L. N.: Effect of the clathrate hydrate environment on the structure of collagen xenograft tissue with chitosan coating deposited from solution in the $\mathrm{H}_{2} \mathrm{O} / \mathrm{CO}_{2}$ system at high pressure. Doklady Chemistry, 468, 195-198 (2016). https://doi.org/10.1134/S0012500816060057

[18] Wehmeyer J. L., Christy R. J., Andrews A. L., Bordano W. N., Natesan S.: Methods of treating amniotic membranes using supercritical fluids and compositions and apparatuses prepared therefrom. U.S. Patent 20140248328 A1, USA (2014).

[19] Sawada K., Terada D., Yamaoka T., Kitamura S., Fujisato T.: Cell removal with supercritical carbon dioxide for acellular artificial tissue. Journal of Chemical Technology and Biotechnology, 83, 943-949 (2008).

https://doi.org/10.1002/jctb.1899
[20] Fages J., Marty A., Delga C., Condoret J. S., Combes D., Frayssinet P.: Use of supercritical $\mathrm{CO}_{2}$ for bone delipidation. Biomaterials, 15, 650-656 (1994).

[21] Sachlos E., Wahl D. A., Triffitt J. T., Czernuszka J. T.: The impact of critical point drying with liquid carbon dioxide on collagen-hydroxyapatite composite scaffolds. Acta Biomaterialia, 4, 1322-1331 (2008).

https://doi.org/10.1016/j.actbio.2008.03.016

[22] Tanaka J., Ikoma T., Yoshioka T.: Non-fibrillar collagen molded body and method for producing same. European Patent EP2644620 A1, EU (2012).

[23] Usha R., Ramasami T.: The effects of urea and $n$-propanol on collagen denaturation: Using DSC, circular dicroism. https://doi.org/10.1016/S0040-6031(03)00335-6

[24] Bürck J., Heissler S., Geckle U., Ardakani M. F., Schneider R., Ulrich A. S., Kazanci M.: Resemblance of electrospun collagen nanofibers to their native structure. Langmuir, 29, 1562-1572 (2013).

https://doi.org/10.1021/la3033258

[25] Mu C., Li D., Lin W., Ding Y., Zhang G.: Temperature induced denaturation of collagen in acidic solution. Biopolymers, 86, 282-287 (2007). https://doi.org/10.1002/bip.20742

[26] Leikina E., Mertts M. V., Kuznetsova N., Leikin S.: Type I collagen is thermally unstable at body temperature. Proceedings of the National Academy of Sciences of the United States of America, 99, 1314-1318 (2002). https://doi.org/10.1073/pnas.032307099

[27] Kim B. S., Choi J. S., Kim J. D., Yoon H. I., Choi Y. C., Cho Y. W.: Human collagen isolated from adipose tissue. Biotechnology Progress, 28, 973-980 (2012). https://doi.org/10.1002/btpr.1555

[28] Schindelin J., Arganda-Carreras I., Frise E., Kaynig V., Longair M., Pietzsch T., Preibisch S., Rueden C., Saalfeld S., Schmid B., Tinevez J-Y., White D. J., Hartenstein V., Eliceiri K., Tomancak P., Cardona A.: Fiji: an open-source platform for biological-image analysis. Nature Methods, 9, 676-682 (2012).

https://doi.org/10.1038/nmeth.2019

[29] Chapman J. A., Tzaphlidou M., Meek K. M., Kadler K. E.: The collagen fibril - A model system for studying the staining and fixation of a protein. Electron Microscopy Reviews, 3, 143-182 (1990).

[30] Gobeaux F., Belamie E., Mosser G., Davidson P., Asnacios S.: Power law rheology and strain-induced yielding in acidic solutions of type I-collagen. Soft Matter, 6, 3769-3777 (2010). https://doi.org/10.1039/b922151d

[31] Yang Y-L., Kaufman L. J.: Rheology and confocal reflectance microscopy as probes of mechanical properties and structure during collagen and collagen/hyaluronan self-assembly. Biophysical Journal, 96, 1566-1585 (2009).

https://doi.org/10.1016/j.bpj.2008.10.063 
[32] Yan M., Li B., Zhao X., Qin S.: Effect of concentration, $\mathrm{pH}$ and ionic strength on the kinetic self-assembly of acid-soluble collagen from walleye pollock (Theragra chalcogramma) skin. Food Hydrocolloids, 29, 199-204 (2012).

https://doi.org/10.1016/j.foodhyd.2012.02.014

[33] Khorshid N., Hossain M. M., Farid M. M.: Precipitation of food protein using high pressure carbon dioxide. Journal of Food Engineering, 79, 1214-1220 (2007). https://doi.org/10.1016/j.jfoodeng.2006.04.037

[34] Tashima A. K., Ottens M., van der Wielen L. A. M., Cintra D. E., Pauli J. R., de Alcântara Pessôa Filho P., Miranda E. A.: Precipitation of porcine insulin with carbon dioxide. Biotechnology and Bioengineering, 103, 909-919 (2009).

https://doi.org/10.1002/bit.22319

[35] Floren M., Bonani W., Dharmarajan A., Motta A., Migliaresi C., Tan W.: Human mesenchymal stem cells cultured on silk hydrogels with variable stiffness and growth factor differentiate into mature smooth muscle cell phenotype. Acta Biomaterialia, 31, 156-166 (2016). https://doi.org/10.1016/j.actbio.2015.11.051
[36] Floren M. L., Spilimbergo S., Motta A., Migliaresi C.: Carbon dioxide induced silk protein gelation for biomedical applications. Biomacromolecules, 13, 2060 2072 (2012). https://doi.org/10.1021/bm300450a

[37] Freudenberg U., Behrens S. H., Welzel P. B., Müller M., Grimmer M., Salchert K., Taeger T., Schmidt K., Pompe W., Werner C.: Electrostatic interactions modulate the conformation of collagen I. Biophysical Journal, 92, 2108-2119 (2007).

https://doi.org/10.1529/biophysj.106.094284

[38] Forgacs G., Newman S. A., Hinner B., Maier C. W., Sackmann E.: Assembly of collagen matrices as a phase transition revealed by structural and rheologic studies. Biophysical Journal, 84, 1272-1280 (2003). https://doi.org/10.1016/S0006-3495(03)74942-X

[39] Bray A. J.: Theory of phase-ordering kinetics. Advances in Physics, 43, 357-459 (1994).

https://doi.org/10.1080/00018739400101505 